\title{
SUBSÍDIOS PARA UMA HISTÓRIA DO DESIGN GRÁFICO NO BRASIL: A PRIMEIRA TIPOGRAFIA DO AMAZONAS (1851-1866)
}

Rômulo do Nascimento Pereira

Escola Superior de Desenho Industrial - UERJ

romulonascimento@hotmail.com

Ligia Medeiros

Escola Superior de Desenho Industrial - UERJ

ligiamsmedeiros@gmail.com

Resumo: Este artigo propõe o estudo do princípio da atividade gráfica no Amazonas a partir dos artefatos produzidos pelo primeiro empreendimento tipográfico do estado, de 1851 a 1866, e de sua relação com os aspectos socioeconômicos e culturais da região. Nesse período observamos a tecnologia gráfica como um espelho no qual uma sociedade em formação reflete, projeta e também silencia, sobre si e seus conflitos. A Tipografia dos Silva Ramos não deixa dúvida quanto a sua dependência das encomendas do governo provincial, a cultura material proveniente de sua oficina é severamente marcada pelos aspectos materiais e técnicos de um modesto empreendimento. $\mathrm{O}$ que nada havia de modesto era o poder da impressão de multiplicar e fixar valores "civilizados" a um vasto e variado território. Essa pesquisa se apoiou nas reflexões propiciadas pelos artefatos impressos e em pesquisa bibliográfica para construir uma breve narrativa que mostra o caminho inicial da atividade gráfica no Amazonas, seus artefatos, projeto e sua relação com a sociedade.

Palavras-chave: história do design gráfico, tipografia, memória gráfica brasileira, Amazonas.

Abstract: This paper proposes the study of the principle of graphic activity
in the Amazon from artifacts produced by the first typographic develop-
ment of the state, from 1851 to 1866, and its relation to the socioeconomic
and cultural aspects of the region. During this period we observe the
graphics technology as a mirror in which a society reflects, designs and also
mutes on themselves and their conflicts. The typography Silva Ramos not
leaves no doubt as to their dependence on orders from the provincial go-
vernment, the material culture from his workshop is severely marked by
material and technical aspects of a modest enterprise. Immodest is the
power of graphics technology multiplying printed artifacts andof the
printing process in the multiply and values "civilized" to a vast and varied
territory. This research was supported in the reflections afforded by printed
artifacts and literature to build a brief narrative that shows the initial path
of graphic activity in the Amazonas, its artifacts, design and its relationship 
with society.

Keywords: graphic design history, typography, Brazilian graphics memory, Amazonas.

\section{UM NOVO COMEÇO}

Na literatura sobre a história do design no Brasil, inclusive nas edições que privilegiam imagens, observa-se a completa falta de referências a artefatos industriais projetados na região Norte, e especificamente no distante Amazonas. Para quem vive na região essa lacuna retrata, além de um desinteresse dos centros enunciadores pela produção de outrem, a falta de pesquisa histórica da área. O que tem levado a um processo de invisibilidade para não dizer exclusão do panorama de design no Brasil. Acreditamos que a história dos artefatos produzidos industrialmente, mesmo antes da formalização da atividade e do profissional de design no Brasil, se constitui um campo fértil para pesquisa, dado a escassez de estudos e a importância de saber sobre o seu passado. O registro sistemático e o estudo da cultura visual e material produzida a partir das relações com a sociedade permite a inserção de mais vozes, com seus sotaques e particularidades, na polifonia nacional de produção e difusão de conhecimento na área de design e outras. Com esse saber será possível entender, ou pelo menos visualizar, elementos que tracem uma ligação dessa atividade com o tempo e o lugar em que se vive, permitindo uma atuação mais segura e rica.

Há, na cidade de Manaus, várias instituições de ensino com cursos de graduação em Design, poucas se dedicam à pesquisa. Embora esse quadro tenha melhorado bastante, nota-se um predomínio de pesquisas analíticas sobre fenômenos atuais, sobretudo dos temas ligados à identidade cultural, design de produto, ergonomia, sustentabilidade e ensino (Oliveira, 2014: 21-24). O conhecimento da própria história não se configura apenas em uma ampliação de repertório, mas antes em uma melhor delimitação do território no qual o design vem atuando, e não de forma isolada. Dentro de um contexto maior tem-se a oportunidade de pensar criticamente sua própria atividade e chegar a um maior domínio de intervenção em sua própria realidade. Ao discorrer sobre as motivações e dificuldades para a realização de seu livro, História da Amazônia, Márcio Souza (2009: 14) afirma: “...escrever História é também exercer escolhas. $\mathrm{E}$ escolher nem sempre é submeter os fatos aos caprichos do narrador. Porque selecionar é uma contingência, não a mera escuta de um eco débil do passado". Mais adiante segue "(...) ter uma História significa existir" (Souza, 2009: 16). Assertivas que se aplicam tanto à construção de uma narrativa para o design quanto a que compomos resumidamente aqui.

Nosso objeto de estudo ainda não mereceu estudos aprofundados, embora a história da imprensa tenha recebido grande atenção no âmbito do Programa de Pós-Graduação em História da Universidade Federal do Amazonas, com relevantes pesquisas e contribuições. Entretanto, o foco das pesquisas tem residido no estudo da imprensa periódica, sua difusão e papel em diversos processos históricos e contextos. Há um considerável registro da atividade jornalística no estado, com indicações importantes sobre estabelecimentos gráficos e o contexto político e social em torno dos jornais. Nessa delimitação de campo o circuito da imprensa pesquisado atingiu de forma mar- 
ginal a indústria gráfica e a cultura visual envolvida, havendo poucas referências à história do livro e de outros impressos. Além disso, os artefatos gráficos são tratados, em muitos casos, como fontes documentais importantes pelo que está impresso em suas folhas de papel, seu conteúdo, sem maior aprofundamento na observação crítica da cultura visual ou mesmo projetual relacionada.

Ao se trabalhar com um tema pouco estudado, as lacunas, dificuldades e questionamentos podem se mostrar difíceis de transpor. Ao mesmo tempo em que o acervo de artefatos descobertos pode revelar grandes lições e uma rica cultura material e visual ainda desconhecida. Dessa forma se fez necessária uma pesquisa em diversos acervos, inclusive digitais, em que foi possível mapear um grande número de fontes a serem consultadas e registradas. Foram pesquisados diversos documentos de interesse, como os pertencentes aos acervos da Biblioteca Nacional e do Instituto Histórico e Geográfico do Brasil, ambos no Rio de Janeiro; em Belém, na Biblioteca Pública Arthur Vianna e no Arquivo Público do Estado do Pará. Em Manaus os acervos da Biblioteca Pública do Amazonas, Biblioteca Mario Ypiranga, Instituto Geográfico e Histórico do Amazonas, Museu Amazônico, e outros. Muito desses acervos não possuem condições adequadas à guarda, manutenção e acesso aos impressos, havendo casos em que muitos dos artefatos correm o risco de se perderem. Esse destino, o desaparecimento, é um fado com que se se deparou com frequência, pois muitos periódicos, livros e impressos estão incompletos ou perdidos, embora se tenha o registro de sua existência. Antes que a lista de desaparecidos aumente pretendemos o resgate dos vários agentes do circuito produtivo das artes gráficas. Os próprios artefatos materiais produzidos são testemunho e objeto da pesquisa. E, junto do estudo das diversas fontes bibliográficas e da reflexão crítica, permitem demarcar melhor o desenvolvimento da atividade gráfica e sua articulação com as demandas da sociedade que os projetaram, produziram, consumiram e hoje mantém a guarda desses documentos. $E$, podemos acrescentar, dessa mesma sociedade que hoje, na fala e pesquisa aqui apresentada quer se mostrar capaz de estudar e valorizar sua história e artefatos.

\section{A PRIMEIRA IMPRESSÃO}

Iniciamos explicitando alguns questionamentos preliminares que orientaram a pesquisa que ora apresentamos: os artefatos materiais resultantes da atividade gráfica no Amazonas, de 1851 a 1866, podem descrever ou fornecer subsídios para um quadro que relacione o início da atividade gráfica com os aspectos socioeconômicos e culturais da região? Quais as características a e cultura material produzida pela indústria gráfica amazonense? Em que medida a utilização do meio impresso foi capaz de influir nos acontecimentos e cotidiano e de refleti-los criticamente? A corroborar a escolha desse período, 1851-1866, temos um arco de 15 anos que vai da elevação do Amazonas à categoria de Província, sua autonomia portanto, até o fechamento do primeiro empreendimento tipográfico. Nesse período, situado historicamente no Brasil no Segundo Reinado, buscamos resgatar uma cultura visual impressa pouco conhecida e mostrar que o próprio artefato impresso vai aos poucos refletir um lento processo que busca criar as bases materiais de um lugar antes subjugado politicamente pela província do GrãoPará e pelo isolamento geográfico. Mas os impressos mostram muito mais.

Outras inquietações vieram da leitura do ensaio de Margolin (2014), intitulado "Problemas narrativos do design gráfico", em que, depois de arrolar uma série de 
trabalhos historiográficos sobre design, afirma o pesquisador que esse conjunto "não resultou em esclarecimento (...) de como o design gráfico foi constituído, nem definiu um curso satisfatório para o desenvolvimento mais pleno de uma estrutura narrativa que pode começar a explicar o design gráfico como prática" (2014: 239). A seguir ele discorre sobre erros, acertos e zonas de conflitos a ser desbravada por quem se aventurar a essa dura tarefa de desenvolver uma história do design gráfico que considere a sua especificidade, complexidade e também suas fragilidades. Forty (2007: 9), por outro lado aponta para a reprodução de juízos já desgastados quanto ao design inglês do século 19 e a permanência de premissas do senso comum no discurso histórico sobre a atividade de design. Autores aos quais podemos juntar Cardoso (2004), a lembrar da importância de se pesquisar a história do design integrando-a ao estudo das relações sociais e econômicas da época em que se situam.

Vários textos nos ajudaram a ver bem mais do que a chegada de uma tecnologia a um periférico lugar do Brasil. Um encontro, de uma atividade humana advinda no século 15 , com uma história que remonta a própria invenção da escrita - a tipografia, com um local "descoberto", ou inventado, pouco depois - El mar Dulce ou o grande rio das amazonas. Lugar que ainda não tinha dominado a escrita e nem se constituía em uma unidade, também com uma história antiga, diversa e culturalmente rica, embora sem deixar maiores registros fixos. Até que esta reunião aconteça, no século 19, muitas caudalosas águas rolaram, nem todas produzindo benéficos efeitos ou grandes realizações.

Por atividade gráfica entenda-se o conjunto de procedimentos técnicos e atividades subsidiárias com o objetivo de reproduzir mecanicamente escritos e imagem, em qualquer número de cópias, a partir de uma matriz (Porta, 1958: 27). No exercício das chamadas artes gráficas diversas etapas precisam ser realizadas, podemos caracterizá-las como: projeto ou criação, em que se recebem os originais e as indicações do artefato a ser produzido, pré-impressão, impressão e acabamento. Essa divisão em etapas está ancorada em um processo que se tornou comum com o tempo, nele a atuação do projetista acontece prioritariamente na fase de criação, com o planejamento e configuração dos produtos gráficos, mesmo nos mais simples. Nas demais, ele atuaria para garantir que o artefato final seja produzido de acordo com as especificações dadas, de acordo com a matriz desenvolvida e corrigida na fase de pré-impressão, com provas prévias e revisão. No período que aqui pesquisado, estas limites ainda não se encontravam claros, muitas vezes cabendo ao mesmo profissional, redigir, compor, imprimir e até comercializar os impressos.

Depois há a vida dos artefatos, sua difusão e apropriação pela comunidade. Os impressos são objetos, sobretudo, de comunicação, eles informam e difundem conhecimentos, nunca de forma isenta ou neutra, inclusive através de sua configuração formal e material. Alguns autores chegam mesmo a situar o desenvolvimento da tecnologia gráfica e da imprensa como sendo a "própria história do desenvolvimento capitalista" (Sodré, 1966: 1). Assim pretendemos iniciar um quadro aproximado de informações da atividade gráfica, seus artefatos e espaço ocupado no meio socioeconômico e cultural do qual faz parte. Talvez mesmo ajudar a compreender como esse trajeto ajudou a formar a vida de uma comunidade humana, com suas especificidades e aspirações, lutas, conquistas, derrotas e mais. Imagens e texto projetados em papel, reproduzindo mais do que uma matriz gráfica: uma forma de se posicionar e ler o mundo e a si. Um processo em que a cultura visual e material ajuda a decifrar, contar e 
a alimentar, pois esse é um caminho que parece não ter ponto final.

\subsection{Abertura de um rio-mar tipográfico}

A tecnologia tipográfica se disseminou rápido a partir da Alemanha, chegou a Portugal ainda no século 15 , e de lá seguiu para as suas possessões coloniais no oriente no século 16. Na terra do pau-brasil a história só pode ser registrada em definitivo em letra impressa no século 19 , mais precisamente com a chegada da própria família real, em 1808. Antes, em 1747, a oficina de Antônio Isidoro da Fonseca no Rio de Janeiro produziu os primeiros impressos na forma de opúsculos, sendo logo proibido. Chegou ao Grão-Pará em 1821, e de Belém viajou pelo rio Amazonas até chegar à província recém-criada e de mesmo nome do rio, em 1851. A chegada da primeira tipografia se dá no contexto de redefinição política da região, em que o Amazonas é elevado à categoria de Província, em 1850. Um tipógrafo atuante em Belém foi convidado pelo primeiro presidente da nova Província, João Baptista Tenreiro Aranha (1798-1861), a instalar sua tipografia na então Cidade da Barra do Rio Negro, atualmente Manaus, o que ocorreu em 1851. Assim, o governo recém-empossado garantiu o fornecimento das condições técnicas e materiais para tornar públicas suas decisões a um vasto, embora despovoado, território. Manoel da Silva Ramos é o nome do proprietário e primeiro tipografo instalado no Amazonas, também o nome que recebe o estabelecimento pioneiro, assinalado, em algumas edições como - Typ. M. da S. Ramos.

Segundo Souza (1908: 87) Manoel da Silva Ramos era tipógrafo experiente, tendo trabalhado antes na oficina de Honorio José dos Santos, em Belém. Na então cidade da Barra, além de ser tenente da Guarda Nacional acumulava seu trabalho na tipografia com o de fiscal da Câmara Municipal, tendo exercido outras atividades, inclusive juiz de paz. Seu empreendimento era modesto, condizente com uma vila de ruas cheias de buracos, casas geralmente de um pavimento, com uma população constituída em grande medida por índios e mestiços, mesmo os ditos brancos não possuíam muita escolarização. Assim foi descrita a capital da província do Amazonas pelo cientista inglês Alfred Russel Wallace que residiu na região por quatro anos, até 1852. 0 que nada havia de modesto era o poder da impressão de multiplicar e tornar pública a voz do governo, o único, nos primeiros anos da província do Amazonas, a poder arcar com os custos desse empreendimento. Wallace (1934: 201) continua:

O comércio local consiste principalmente na exportação de castanhas, salsaparrilha e peixe, e as importações são tecidos europeus, de inferior qualidade, cutilaria ordinária, colares, espelhos e outras bugigangas mais, para o comércio com as tribos indígenas, das quais a cidade é o quartel-mestre.(...) A maior parte nunca abre um livro ou trata de empregar o seu tempo em qualquer outra ocupação intelectual.

Nessa descrição da cidade e da população da província do Amazonas não podemos deixar de observar seu caráter eurocêntrico, ignorando outras formas de produção intelectual que não as estabelecidas no seu local de origem. A cultura oral e as diversas tradições, comuns à época na região, eram as principais fontes de saber e transmissão de conhecimentos, utilizando a Língua Geral Amazônica - o Nheengatu, e diversas outras. No entanto, era para essa modernidade "letrada" que tentava caminhar a recém-criada província, agora de posse de uma tecnologia propícia a isso. O primeiro jornal impresso, o Cinco de Setembro, começa a circular uma vez por semana a partir de três de maio de 1851 e atendia claramente a uma demanda institucional. Os 
poucos moradores, mesmo portugueses, eram em sua maioria analfabetos. Decorridos oito meses, o jornal passa a se intitular Estrella do Amazonas, e como assinala seu primeiro editorial, de sete de janeiro de 1852:

...com a posse do exmo. sr. Presidente Aranha e a instalação da província, uma nova estrela apareceu no diadema imperial, para sem inveja das demais enriquecel-o. A nossa marcha será a mesma que té agora temos seguido; esforçando-nos quanto em nossas forças couber para tornar instructivas e uteis as publicações que fizermos. (...) Contamos com a coadjuvação dos briosos Amazonienses e esperamos merecer a alta protecção do Exm. Governo da Provincia, sem a qual não podemos continuar.

O editorial não deixa dúvidas quanto à dependência deste periódico da "proteção" do governo da província. Em 1854, circulava normalmente aos sábados, e algumas vezes em outros dias da semana em edições especiais, tendo em média três de suas quatro páginas ocupadas com a matéria da "Seção Oficial", a principal do jornal. Havia ainda a seção "Estrella do Amazonas", com diversas notícias curtas, tanto sobre a família imperial, como sobre as importantes chegadas das embarcações. Com essas vinham notícias do resto do país, que, na edição de 14 de janeiro de 1854, foram assim resumidas: "Os Jornaes que recebemos da Côrte e Provincias nada referem de extraordinário". Além dessas, com alguma frequência havia inserções com os títulos de Aviso, Annuncios, Editaes, Movimento de Porto e outras. As notícias e as informações de interesse particular, como as despedidas, os anúncios de produtos ou serviços, da fuga de escravos, toda a comunicação cotidiana ocupando poucas linhas no final do periódico, chegando a ser inexistente alguns exemplares, ocupado todo por matéria oficial.
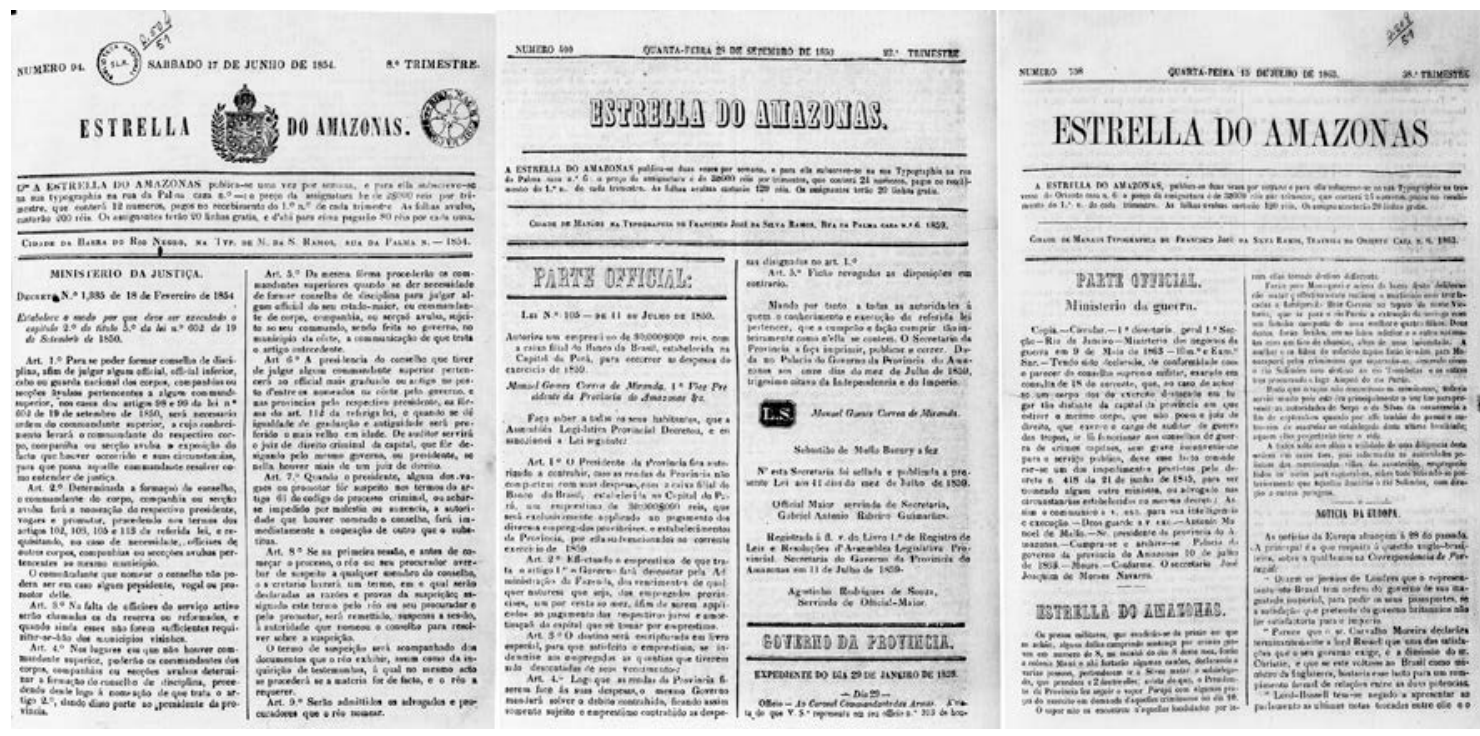

Figura 1 - Capas do jornal Estrella do Amazonas: em 1854, com brasão imperial do Brasil; ao centro, em 1859, título composto em tipos outline; e em 1863, título composto em tipos serifados.

Fonte: Elaborado a partir de exemplares digitalizados pela Biblioteca Nacional.

No Estrella do Amazonas, em 1854, observamos o constante emprego do brasão imperial em sua capa, e de poucos recursos gráficos como a utilização de fios, capitulares e a utilização de tipos compostos em versalete, itálico, versal, tipos display, o emprego de ligaduras e de poucas vinhetas tipográficas. Um simples colofão, composto em apenas uma linha, fechava a edição composta por apenas uma folha de papel dobrada ao meio, formando quatro páginas, com mancha gráfica dominada pela com- 
posição do texto corrido em duas colunas. Essa estrutura visual básica se manteve durante o período em que o jornal foi produzido, com alterações mais marcantes apenas na mudança dos tipos do título e do texto. Em 1854, o cabeçalho do jornal exibe o brasão imperial do Brasil e compõe o título do periódico em tipos serifados estreitos (Fig. 1). No mesmo cabeçalho há a utilização de uma pequena vinheta tipográfica, uma mão indicativa, assinalando o valor da assinatura do jornal. O brasão imperial sai da capa ainda em 1856.

Na página dois da edição de número 141, publicada na quarta-feira dia 30 de abril de 1856 o Estrella do Amazonas reporta sua dificuldade de acomodar as notícias de interesse comum e mesmo a correspondência, ao mesmo tempo em que tem um grande volume de espaço ocupado pelas peças oficiais. Para tentar minimizar o descontentamento e a curiosidade dos leitores: “...adoptamos de ora em diante hum outro typo que offereça maior espaço ás nossas publicações". No mesmo número continua sua auto avaliação: "A falta absoluta de pessôal sufficiente e habilitado para dar vazão á maiores, e mais regulares trabalhos de nossa Imprensa tem sido a cauza principal de havermo-nos conservado em hum estado quazi por bem dizer apathico..." Apesar da falta de pessoal qualificado o jornal informa ainda que a partir de junho desse mesmo ano, começará a circular duas vezes por semana. Significativa mudança, pois altera a dinâmica do trabalho na oficina, aumentando a complexidade do fluxo de composição da tipografia, que ainda publicava edições, opúsculos e outros impressos para o governo da província. O volume de trabalho da primeira, e por muitos anos a única, oficina tipográfica do Amazonas parece sempre ter sido grande, como fica patente na edição do Estrella do Amazonas de 2 de agosto de 1856:

Por affluencia de trabalhos e falta de pessoal não foi possivel a impressão desse jornal no dia 30 do passado, e emquanto estivermos com a impressão do relatorio do Ex.mo Snr. Presidente da Provincia, terá publicação só uma vez por semana. Pedimos ao publico desculpa por esta falta...

Em julho de 1856, quem assume o comando da tipografia é Francisco José da Silva Ramos, irmão do primeiro tipógrafo. Nos exemplares examinados identificamos a utilização de poucas vinhetas tipográficas: brasão do Império, mão indicativa, embarcação a vela, navio a vapor, escravo e escrava em fuga, edificação, anjo fúnebre, águia, alguns desses com variações de desenhos (Fig. 2). Com exceção do brasão e da mão, que foram usados repetidamente no cabeçalho principal, todas as outras vinhetas foram empregados pouquíssimas vezes, e sobretudo nas seções de Avisos ou Annuncios. Também de forma bem episódica tem-se alguns anúncios que demonstram um padrão gráfico mais acabado, constituindo-se em exceções. Podemos conjecturar que essa pouca variação no discurso gráfico seja devida às grandes dificuldades, tanto materiais, como a carência de tipos e material gráfico, quanto de tempo e mesmo técnica. Além é claro da falta de concorrência de periódicos e de um maior público leitor. Outra lacuna identificada no periódico foi a falta de referência à Língua Geral da Amazônia, idioma falado pela absoluta maioria dos seus habitantes. Na hemeroteca digital da Biblioteca Nacional do Rio de Janeiro buscamos a ocorrência da expressão "língua geral" e nas quase quinhentas edições do Estrella digitalizadas pela instituição encontramos apenas três ocorrências dela. Em uma delas, de 30 de abril de 1856, um anúncio de fuga de escravo, onde, ao caracterizar João Mulato "(puxando mais a tapuio)", o anunciante diz que este tem escrito nos rosto, em "lingoa geral", a palavra escravo. Impressa com crueldade na carne, mas não no papel. 


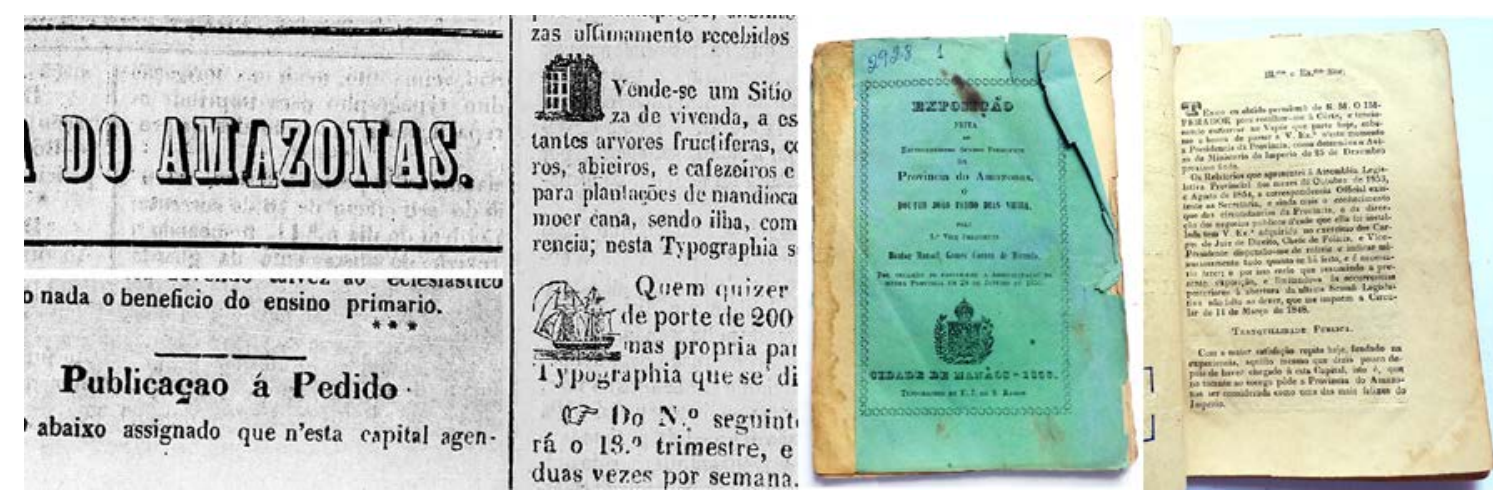

Figura 2 - À esquerda, jornal Estrella do Amazonas: erro de composição no segundo "A" de Amazonas, a sombra está projetada no sentido oposto; abaixo, a improvisação do número "5" invertido para substituir o cedilha, e detalhe de vinhetas tipográficas da seção Avizos. À direita, Capa da Exposição feita ao Excellentissimo senhor..., edição de 1856 e página interna com capitular de Exposição..., 1860. Fonte: Fotomontagem elaborado pelos autores a partir da pesquisa.

No início de 1857, o jornal altera os tipos de seu cabeçalho, utilizando tipos de serifa quadrada, outline e com sombra. Cinco anos depois, em 1862, outra alteração, novamente usando tipos serifados de alto contraste entre seus traços (Fig. 1). Na seção Aviso, na edição de 3 de novembro de 1858, há o registro da passagem pela cidade de um fotógrafo, Hipolito Mainette, que oferece no jornal "retratos pelos systema Daguerreotypo". Pelas prestações de contas publicadas no Estrella do Amazonas observamos que o serviço de encadernação necessário a algumas Secretarias de Governo era realizado no Estabelecimento dos Educandos Artífices. Instituição que acoIhia menores sem família ou de poucos recursos, e ainda crianças indígenas para adquirirem educação e um ofício, muitas vezes contra a vontade.

A grande maioria dos exemplares de periódicos examinados nessa pesquisa se deu a partir de digitalizações, nas poucas edições manuseadas observou-se que a tinta não tem um aspecto homogêneo ao longo das páginas, nem mesmo entre os parágrafos de uma mesma página. Além disso, os tipos parecem terem sido pressionados em demasia contra a fina superfície do papel, caracterizando, a nosso ver, um processo de impressão rudimentar. Característica também comum às edições publicadas por essa oficina tipográfica, constituída de obras modestas e poucos recursos gráficos. Na Typographya de Manoel da Silva Ramos e depois na Typ. de Francisco José da Silva Ramos publicaram-se muitas edições com títulos de: Exposição apresentada por...; Falla dirigida à...; Roteiro..., dentre outros, dirigidas ao presidente da província ou à Assembléia da província, ou seja, títulos de interesse restrito. Possuem um padrão gráfico simples como o Estrella, com capa impressa em papel de cor, composta em tipos variados, sempre de forma centralizada [Fig. 2]. Fazendo uso, em algumas obras, do brasão imperial do Brasil ou de uma vinheta decorativa, mais raramente uma cercadura, composição que se repetia na folha de rosto. O miolo era diagramado de maneira direta, com boas margens e entrelinhamento correto, quase sem decoração, apenas uma capitular a iniciar o texto, este sempre composto em tipos serifados, tendo ao final o colofão.

As edições de literatura ou de particulares residente na província eram comumente publicadas em outras províncias ou mesmo em outros países, como Portugal e França. Por exemplo, Simá: romance histórico do Alto Amazonas, de Lourenço da Silva Araujo Amazonas, foi editado em Recife na Typ. de F. C. de Lemos e Silva, em 1857. 
Prática comum, mesmo em outras províncias. No entanto, esse parecia ser o único caminho a seguir para uma publicação particular no Amazonas onde, por bastante tempo, houve apenas um empreendimento tipográfico. Encontramos variados erros e improvisações de composição tipográfica, inclusive no cabeçalho do periódico, em alguns números seu título foi impresso composto sem espaço entre as palavras ou com tipos trocados, falhas de composição observadas mais comumente no corpo do texto [Fig. 2]. Em 28 de setembro de 1859, assim se justificou quanto aos erros: "O Official da Secretaria encarregado de ver as provas do expediente do Governo demora demasiadamente sua revisão, o que faz com que ora se publica saia sem ella: faz-se esta declaração para não recaia sobre a Typographia os erros que aparecerem".

Ao discorrer sobre tecnologia e pesquisas sobre o tema, Bonsiepe (2011: 21) chama atenção para a ausência da dimensão projetual no discurso, discorre-se sobre tecnologia sem detalhar o que é feito a partir dela, ou sobre as possibilidades de meIhoria na vida cotidiana propiciados pela industrialização. Na indústria gráfica tem-se claro a face econômica e política que ela mostra nos impressos, ao reduzir custos imprimindo mais, e ao disseminar opiniões que influenciam nos acontecimentos, poder desde cedo utilizado e fiscalizado por governos e religiões. Mas neste primeiro instantâneo, criticamente aqui registrado, não se pode deixar de observar o uso particular que se fazia, embora de forma marginal, do meio impresso. Uma comunicação que era de vital importância para vida de uma comunidade a beira de um grande rio e floresta, e de um isolamento ainda maior. Na seção "Avisos" era comum a publicação das despedidas: notas curtas comunicando a partida de pessoas ou famílias para outras províncias do Brasil, e pedindo aos credores, caso houvessem, que se apresentassem antes da partida. Esse registro fixo em papel seguia para as outras cidades e vilas, fazendo circular assim recados variados, informavam da breve chegada ou partida das embarcações e pessoas, fofocava-se inclusive. Nele também eram feitos diversos anúncios de produtos e serviços, ainda sem muitos recursos visuais ou retóricos.

A diversidade de artefatos impressos foi sendo ampliada lentamente, poucos periódicos surgiram no período observado: $O$ Vigilante, de setembro de 1859, com nove números; o Chechéo, de novembro de 1861, com apenas quatro edições. Somente em 14 de março surge o quinto periódico da província do Amazonas, O Cathechista, título também de sua tipografia, um empreendimento que conseguiu manter-se em atividade até 1871, tornando-se influente (Souza, 1908: 10). Esse mesmo periódico, em 1863, apresentou um projeto gráfico bastante distinto do Estrella do Amazonas. Projetado em três colunas e sem o grande volume da comunicação oficial em suas quatro páginas, uma clara mudança no discurso visual da época.

Em 1866 falece Francisco José da Silva Ramos, proprietário e editor da Estrella do Amazonas, após o que a sua tipografia foi arrematada de sua viúva e o Estrella deixou de brilhar, ou melhor, de ser publicado. Em seu lugar foi editado O Amazonas, oitavo jornal publicado na província do Amazonas, e o mais longevo, embora com mudanças de nome, orientação política e períodos de descontinuações, este vai permanecer até 1921. Todos os periódicos anteriores, a exceção do Estrella do Amazonas e de $O$ Catechista, tiveram pouquíssimos números. Essa é uma característica marcante no período observado, o pequeno número de publicações e as grandes dificuldades de sustentação econômica. Para completar a lista e confirmar a que acabamos de dizer, o sexto periódico foi $O$ Progressista, e o sétimo tinha por título Sensitiva, ambos de 1863 e de poucos números. 


\section{CONSIDERAÇÕES, E ALGUNS PONTOS, FINAIS}

Buscamos observar e refletir neste artigo sobre o período do estabelecimento de instituições e práticas sociais, tecnológicas e culturais antes inexistentes em uma comunidade humana. A introdução da tecnologia tipográfica é parte dessa dinâmica ainda bastante limitada pelas condições econômicas, sociais e culturais da distante e ainda isolada província do Amazonas. De 1851 até o final da década de 1860, tem-se um período de implantação e de lenta difusão da tipografia, mas não apenas. Importante salientar que a educação formal nas escolas ainda atingia uma pequena parcela da população, que se utilizava em grande medida da cultura oral, que associado ao isolamento geográfico tornava improvável o sucesso da aventura gráfica. A impressão conseguiu sobreviver, como destacado aqui, em razão das constantes encomendas do governo provincial, e a partir dessa situação começa a ampliar seu alcance pelas lentas mudanças econômicas e sociais em curso. A navegação no grande rio Amazonas foi liberada a nações amigas em 1866, e as linhas regulares de embarcações a vapor vindas de outros países ainda demoraram a se estabelecer. Transporte por onde circulavam pessoas, bens, mas também informações, propicinado a ligação com outros circuitos culturais. Portanto a atividade gráfica ainda buscava um mercado estável para se consolidar e o reflexo dessa atividade na sociedade era ainda bastante limitado. Não se pode deixar de observar seu uso, junto principalmente com a educação, como elementos de uma estratégia de domínio cultural e político. Em 1866, com o funcionamento da tipografia do jornal Amazonas; e em $1869 \mathrm{com}$ a tipografia do Commercio do Amazonas, de propriedade de Gregorio José de Moraes, teremos uma maior difusão do artefato impresso, pois alguns impressos que necessitavam de melhor acabamento começam a ser produzidos em Manaus. Ampliando assim o corpo técnico e material necessário inclusive para produzir as primeiras edições literárias na década de 1860, e os almanaques da província, em 1870 e 1871. Esses almanaques e outros impressos que encontramos parecem ainda não terem sido registrados, seja em livros ou em pesquisas e estão sendo objetos de estudo que pretendemos divulgar ao dar continuidade a presente pesquisa.

A primeira tipografia do Amazonas produz um conjunto de artefatos impressos com um projeto gráfico modesto, mas não desprovidos de recursos, como tentamos demonstrar. São, sobretudo, produtos impressos que buscam informar claramente um conteúdo ainda bastante limitado quanto a sua diversidade, empregando para tal poucos elementos gráficos ou de retórica visual, embora estes estejam presentes. Seja em uma diagramação que respeita a necessidade de boas margens e de um entrelinhamento mínimo para o conforto da leitura, ou fazendo o uso de fios, tipos displays e ligaduras. Embora tenha poucas variações de estilo, tanto no Estrella do Amazonas quanto nas edições dos Silva Ramos, observa-se, até por meio do discurso, que os seus responsáveis estavam cientes de suas limitações materiais e dificuldades técnicas. Estas apareciam claras no corpo de impressos estudados, seja na forma de improvisações, falhas de composição ou revisão, e até mesmo no que deixou de ser impresso. Muitos impressos, seja de particulares ou do governo, foram produzidos em outras províncias ou no exterior. Esse espelho da sociedade é também importante pelo que não mostra, seja pela falta de espaço físico nas quatro páginas do periódico ocupado pelo olhar oficial que reproduz, seja pela incapacidade de registro de uma cultura não letrada e tão presente no período em que a tipografia se estabeleceu. 
A tipografia Silva Ramos, primeiro de Manoel e depois de seu irmão Francisco, foi um empreendimento eminentemente utilitário, de uso quase exclusivo do governo provincial, fornecendo o meio para divulgar as decisões e a burocracia do governo. Os artefatos produzidos trazem impressos em sua visualidade simples a justeza material e técnica com que eram feitos, assim como de seus declarados objetivos. Dar ciência, marcar o papel com as decisões de cunho político e administrativo da província recémcriada. E, quando houvesse espaço, nem sempre houve, fazer circular informações de interesse geral ou cotidiano, ou mesmo culturais, de seu ainda restrito público leitor. $\mathrm{A}$ floresta de variadas tradições, em sua maioria advindas da cultura oral, começa a ter de ler e a se relacionar de maneira direta com um símbolo de modernidade, a letra impressa.

Não podemos deixar de notar nessa periférica oficina tipográfica no meio da distante terra das amazonas o alinhamento a uma marcha econômica, social e estética já em sua forma globalizada. O impresso traz marcado em si sua origem longínqua - a escrita, depois temos uma tecnologia surgida em outro continente e difundida rapidamente pelo mundo com sua linguagem e tradição. Formalizando o texto e as ideias em uma configuração morfológica específica. A tipografia reproduz de forma padronizada uma língua, e possibilita a expansão de toda uma cultura letrada e uma forma de ver o mundo mediada pela informação impressa. Um movimento que não pode ser detido, e foi capaz de introduzir significativas mudanças com apenas um empreendimento tipográfico de modestas proporções. Artefatos impressos já circulavam pela região, sobretudo com as ordens religiosas e com os poucos leitores alfabetizados. Mas, a partir de 1851, estes produtos do engenho humano são então projetados, produzidos, comercializados localmente, fazendo o impresso circular com seu sotaque local em um vasto território ainda alheio a ele.

Esse é apenas o prólogo, o início da aventura gráfica no Amazonas, em que se buscou o registro dos agentes, práticas, a descrição da cultura material e visual de uma atividade econômica e social ainda incipiente. Percurso que se dirige a uma maior diversificação e complexidade dos artefatos impressos produzidos localmente. Apesar de sua frágil capacidade de resistir ao tempo, muitos artefatos impressos da época sobreviveram, vários números do periódico Estrella do Amazonas e dezenas de edições, e hoje, aos dezesseis anos do século 21 testemunham bem mais do que o texto tatuado em seu corpo diz. Outra história, gráfica, visual, humana e que pretendemos continuar descobrindo e relatando.

\section{REFERÊNCIAS}

BRAGA, Genesino. Nascença e vivência da Biblioteca do Amazonas. Belém: Falangola, 1957.

BENCHIMOL, Samuel. Amazônia - Formação social e cultural. 3. ed. Manaus: Valer, 2009.

BONSIEPE, G. Design, Cultura e Sociedade. São Paulo: Blucher, 2011.

BHABHA, Homi K. O local da cultura. Belo Horizonte: UFMG, 1998.

CALIRI, Jordana Coutinho. Folhas da Província: a imprensa amazonense durante o período imperial (1851-1889). 2014. 151 f. Dissertação (mestrado) - Universidade Federal do Amazonas, Curso de Pós-graduação em História. 
CANCLINI, Nestor Garcia. Culturas híbridas: estratégias para entrar e sair da modernidade. São Paulo: Editora da Universidade de São Paulo, 2008.

CARDOSO, Rafael. Uma introdução à história do design. São Paulo: Blucher, 2004.

CHARTIER, Roger. A aventura do livro: do leitor ao navegador. Conversações com Jean Lebrun. São Paulo: Unesp / Imesp, 1999.

ESTRELLA do Amazonas. Manáos: Typ. de S. Ramos / Typographia de Francisco José da Silva Ramos, 1854 a 1863. Disponível na internet por http em: <http://bndigital.bn.br/ acervo-digital/estrella-amazonas/213420>. Acesso em 10 abr. 2016

FEBVRE, Lucien; MARTIN, Henri-Jean. 0 aparecimento do livro. São Paulo: Unesp / Hucitec, 1992.

FORTY, Adrian. Objetos de desejo - design e sociedade desde 1750. São Paulo: Cosac Naif, 2007.

FREIRE, José Ribamar Bessa (coord). Cem Anos de Imprensa no Amazonas (18511950). Manaus: Editora Calderaro, 1990.

FREIRE, José Ribamar Bessa. Da Língua Geral ao Português: para uma história dos usos sociais das línguas na Amazônia. Rio de Janeiro, UERJ, 2003. 239 f. Tese (Doutorado) da Universidade do Estado do Rio de Janeiro, Instituto de Letras Rio de Janeiro.

HALLEWELL, Laurence. O livro no Brasil. Sua história. 2. ed. São Paulo: Edusp, 2005. HEITLINGER, Paulo. Tipografia: origens, formas e usos das letras. Lisboa: Dinalivro, 2006.

HISTÓRIA da tipografia no Brasil. São Paulo: Masp / Secretaria da Cultura e Tecnologia do Governo do Estado de São Paulo, 1979.

LESCHKO, Nadia Miranda; et all. Memória Gráfica Brasileira: notícias de um campo em construção, p. 791-802. In: Anais do 11으 Congresso Brasileiro de Pesquisa e Desenvolvimento em Design. São Paulo: Blucher, 2014.

MARGOLIN, Victor. A política do artificial: ensaios e estudos sobre design. Rio de Janeiro: Record, 2014.

MEGGS, Philip B.; PURVIS, Alston W. História do design gráfico. São Paulo: Cosac Naify, 2009.

MELO, Chico Homem de; RAMOS, Elaine. Linha do tempo do design gráfico no Brasil. São Paulo: Cosac Naify, 2012.

OLIVEIRA, Alexandre (org.). Pesquisa em Design no Amazonas: ideias, desafios e perspectivas. Manaus: Editora Valer / Fapeam, 2014.

PINHEIRO, Maria Luiza Ugarte. Folhas do Norte: letramento e periodismo no Amazonas (1880-1920). Manaus: Edua, 2015.

PORTA, Frederico. Dicionário de artes gráficas. Porto Alegre: Editora O Globo, 1958.

SODRÉ, Nelson Werneck. A História da Imprensa no Brasil. Rio de Janeiro: Civilização Brasileira, 1966.

SOUZA, João Baptista de Faria e. A imprensa no Amazonas. Manaós: Typographia da Imprensa Official, 1908. 
SOUZA, Márcio. A História da Amazônia. Manaus: Editora Valer, 2009.

Wallace, Alfred Russel. Viagem pelo Amazonas e rio Negro. Série Brasiliana vol. 156. São Paulo: Cia Ed. Nacional, 1939. 